\title{
A geometric method for nipple localization
}

\author{
Humayun Ayub Khan FRCS, Ardeshir Bayat PhD MRCS
}

HA Khan, A Bayat. A geometric method for nipple localization. Can J Plast Surg 2008;16(1):45-47.

BACKGROUND: An important part of preoperative assessment in breast reduction surgery is to locate the site of the nipple-areola complex for the newly structured breast. Inappropriate location is difficult to correct secondarily. Traditional methods of nipple localization taught and practiced suggest the nipple to be located anterior to the inframammary fold. Trying to project this point on the anterior surface of the breast requires either large calipers or feeling the posteriorly placed finger on the anterior surface of a large breast. This certainly introduces some subjectivity to the calculation.

OBJECTIVES: To introduce an easy and accurate method of nipple localization to reduce the learning curve for trainee surgeons.

METHODS: Aesthetic placement of the nipples is at the lower angles of an equilateral or a short isosceles triangle on the chest with its apex at the sternal angle. This triangle can be thought of as two right-angled triangles with their Y-axis on the median plane. The base and vertical limb are measured, and the hypotenuse is calculated. The location of the lower angle is marked on the anterior surface of the breast and represents the new position of the nipple.

RESULTS: Forty patients had nipple localization performed in the above-described manner, with satisfactory placement of the nippleareola complex.

CONCLUSIONS: The above technique introduces some objective measurements to the localization of the nipple in breast reduction surgery. It is easy to practice, and infuses confidence in trainees marking their initial breast reductions.

Key Words: Breast reduction; Nipple localization

\section{Méthode géométrique de localisation du mamelon}

CONTEXTE : Une partie importante de l'évaluation préopératoire dans la plastie de réduction mammaire est la localisation de la plaque aréolomamelonnaire du sein nouvellement structuré. Une mauvaise localisation est difficile à corriger par la suite. D'après les méthodes classiques de localisation du mamelon, enseignées et pratiquées, celui-ci se trouve en position antérieure par rapport au pli inframammaire. Ainsi, la projection du point sur la face antérieure du sein exige de grosses pinces ou encore la sensation du doigt en position postérieure sur la face antérieure d'un sein volumineux. Cela introduit certainement une part de subjectivité dans le calcul.

BUT : Létude avait pour but de concevoir une méthode facile et précise de localisation du mamelon afin de réduire la courbe d'apprentissage des jeunes chirurgiens.

MÉTHODE : Une position esthétique des mamelons se situe aux angles inférieurs d'un triangle équilatéral ou d'un petit triangle isocèle formé sur la poitrine, dont le sommet se trouve à l'angle sternal. On peut imaginer ce triangle comme deux triangles rectangles ayant leur axe des ordonnées sur le plan médian. On mesure ensuite la base et le côté vertical, puis on calcule l'hypoténuse. La place de l'angle inférieur est marquée sur la face antérieure du sein et représente la nouvelle position du mamelon.

RÉSULTATS : La localisation du mamelon a été ainsi effectuée chez 40 patientes, et la nouvelle méthode de calcul a donné des résultats satisfaisants en ce qui concerne la position de la plaque aréolo-mamelonnaire. CONCLUSION : La technique décrite ci-dessus introduit des mesures objectives de localisation du mamelon dans la plastie de réduction mammaire. Elle est facile à appliquer et rassure les stagiaires qui en sont à leurs premiers marquages.
R reast reduction is a very common procedure in plastic surBgery units. An important part of the operation is the preoperative breast markings and positioning of the new nipple-areola complex (NAC). It should be at, or just above, the level of the inframammary fold (IMF). A high placement of the nipple will produce a visually poor appearance and may be difficult to revise.

The acceptable location of the nipple is thought to be at the lateral angles of the base of a triangle. This triangle itself can be thought of as two right-angled triangles standing together with their combined apices at the sternal notch (Figure 1)

We present a technique in which an accurate placement of the NAC can be assessed quickly and easily by calculating the hypotenuse of the two right-angled triangles marked on the breasts of the patient (Figure 2).

\section{TECHNIQUE}

Following the geometric principle of Pythagoras to calculate the length of the hypotenuse, the new position of the NAC on the breast can be located with minimal equipment. This is easily reproducible on both breasts.

With the patient standing, the IMF is marked on both breasts from the medial to lateral extremes. The median sternal line is marked as a straight line drawn from the sternal notch to the umbilicus. The aesthetic breast meridian is marked as generally recommended (ie, starting at the midclavicular point but developing a slight lateral offset from the midclavicular line lower down). This line is continued on the inferior surface of the breast to transect the IMF at point B (Figure 2), averaging approximately $8 \mathrm{~cm}$ to $10 \mathrm{~cm}$ (depending on the frame of the patient) away from the median sternal line. Point B is then 


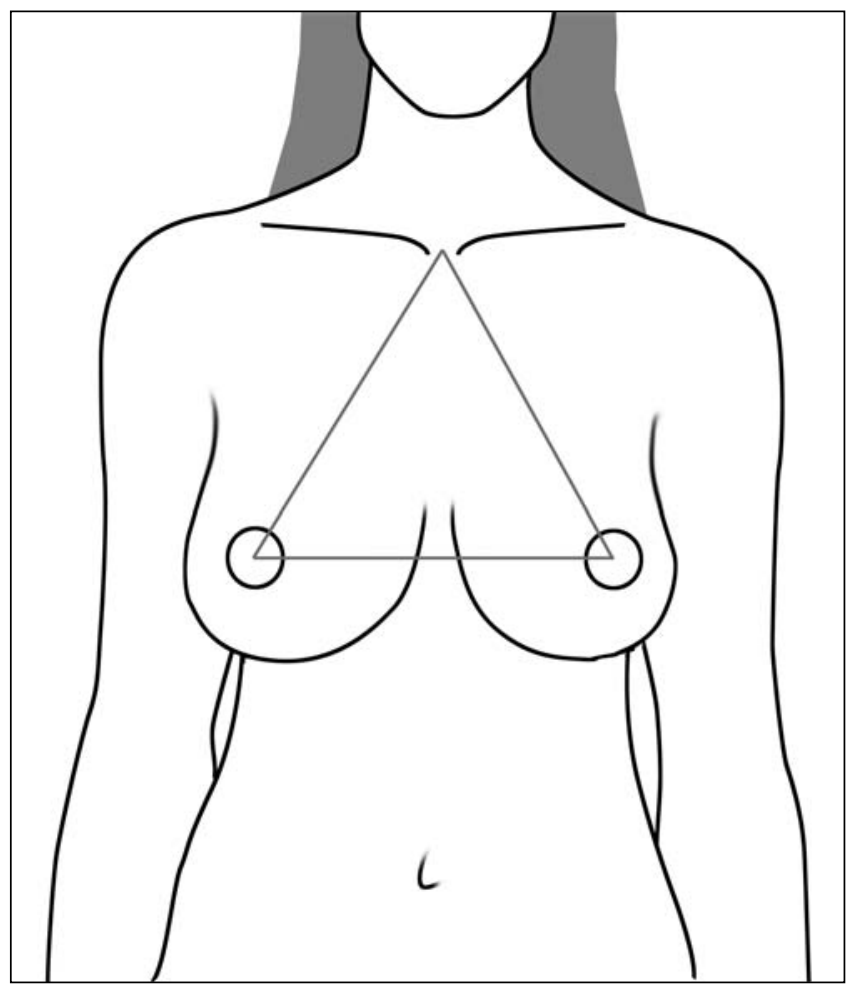

Figure 1) Equilateral triangle representing an aesthetic location of the nipples

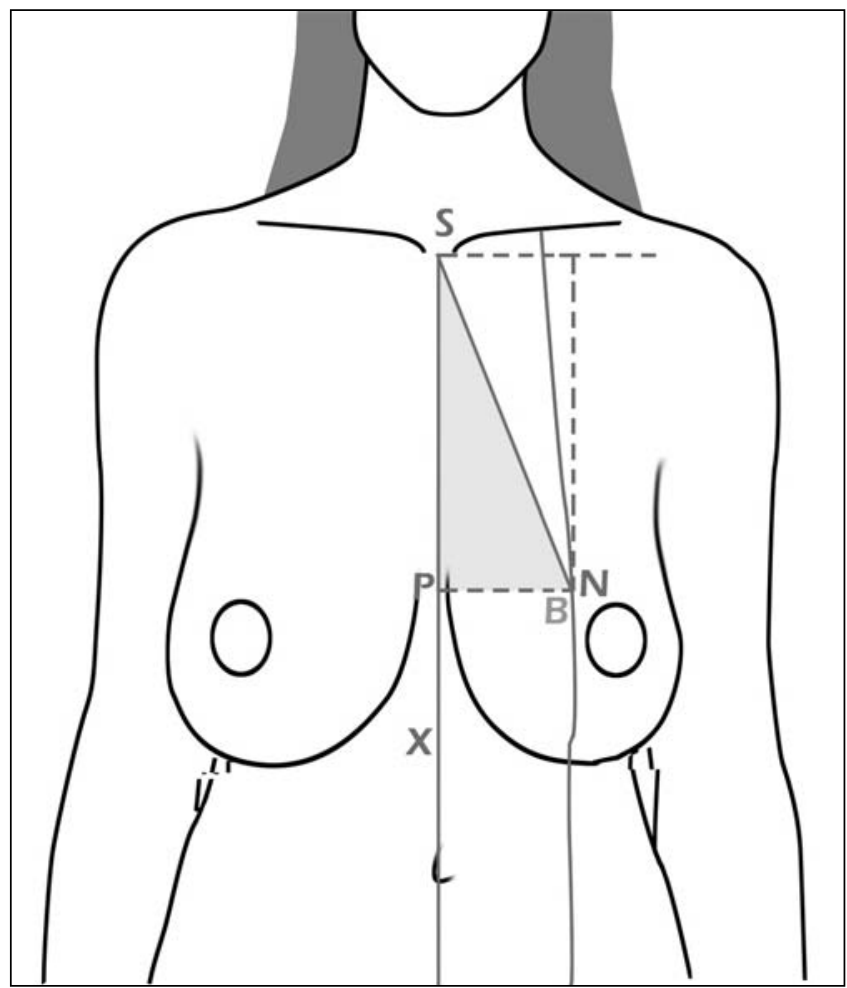

Figure 2) Point B is at the junction of the breast meridian and inframammary fold. Point $N$ (new position of the nipple), on the breast meridian, is calculated by the formula $S N^{2}=P B^{2}+S P^{2}$, where $S N$ represents the sternal notch to nipple distance (location of the new nipple); SP is the sternal notch to level of inframammary fold distance, and PB is the medial sternal line to the transection of the breast meridian on the inframammary fold. $N$ can also be located by dropping a perpendicular line of the same length as SP, from a horizontal line transecting point S. SX is the median line passing through the sternal notch and umbilicus $(X)$
TABLE 1

Calculating distance from the sternal notch to the new nipple using the geometrical calculation of Pythagorus*

\begin{tabular}{lccc}
\hline Median & \multicolumn{3}{c}{ PB, cm } \\
\cline { 2 - 4 } SP, cm & $\mathbf{8}$ & $\mathbf{9}$ & $\mathbf{1 0}$ \\
\hline 18 & 19.7 & 20.1 & 20.6 \\
19 & 20.6 & 21.0 & 21.5 \\
20 & 21.5 & 22.0 & 22.4 \\
21 & 22.5 & 22.8 & 23.2 \\
\cline { 2 - 4 }
\end{tabular}

${ }^{*} S N^{2}=P B^{2}+S P^{2}$, where $S N$ represents the sternal notch to nipple distance (location of the new nipple); SP is the sternal notch to level of inframammary fold distance, and $P B$ is the medial sternal line to the transection of the breast meridian on the inframammary fold

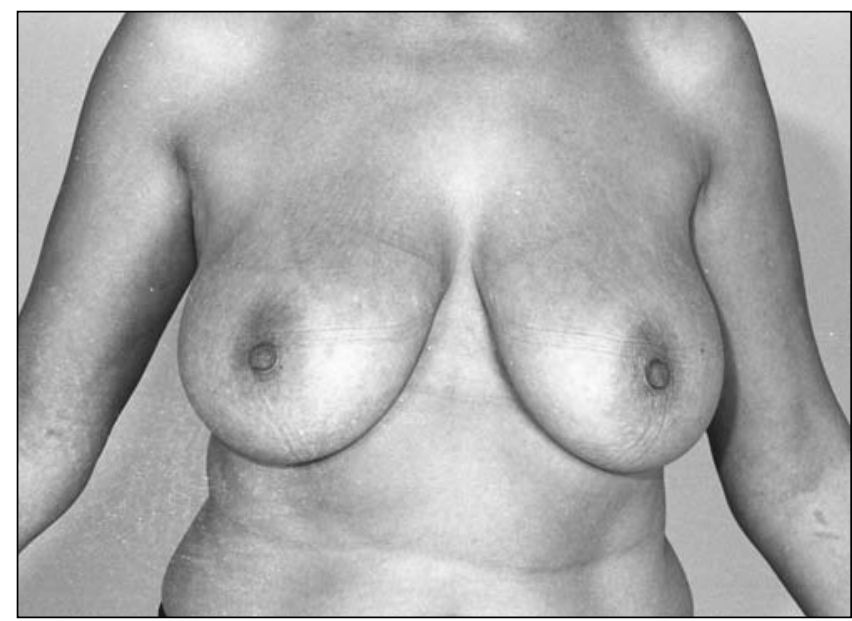

Figure 3) Preoperative photograph showing ptosis and lateral shifting of nipple-areola complex

projected horizontally to the median sternal line to meet it at point $\mathrm{P}$. The lines PB and SP thus represent the base and vertical limbs of a right-angled triangle (Figure 2). These lines are measured with a measuring tape.

Using the geometrical calculation of Pythagoras, $\mathrm{SN}^{2}=\mathrm{PB}^{2}$ $+\mathrm{SP}^{2}$, the length of $\mathrm{SN}$ (the hypotenuse of the triangle or the distance between the sternal notch and new position of the nipple) can be easily calculated using a pocket calculator or, for convenience, referring to a previously calculated table of different measurements of the two short limbs of the right angled triangle (Table 1). Point $\mathrm{N}$ would then represent the anterior transposition of point $\mathrm{B}$, on the previously drawn aesthetic breast meridian (Figure 2). Point $\mathrm{N}$ can also be located by dropping a vertical line, equal to SP on to the breast meridian. The starting point of this line is on a horizontal line passing through point $S$ and a distance SB from point $S$ (Figure 2).

The authors have used the present technique of nipple localization with their preferred method of breast reduction (the inferior pedicle technique) (Figures 3 and 4). All cases over the past 12 months have undergone breast reduction surgery using the above technique for nipple localization. To date, optimal localization of the nipple position has been achieved using this simple technique.

\section{DISCUSSION}

According to Penn (1), the most aesthetic location at which nipples should be placed is at the two basal angles of an imaginary 


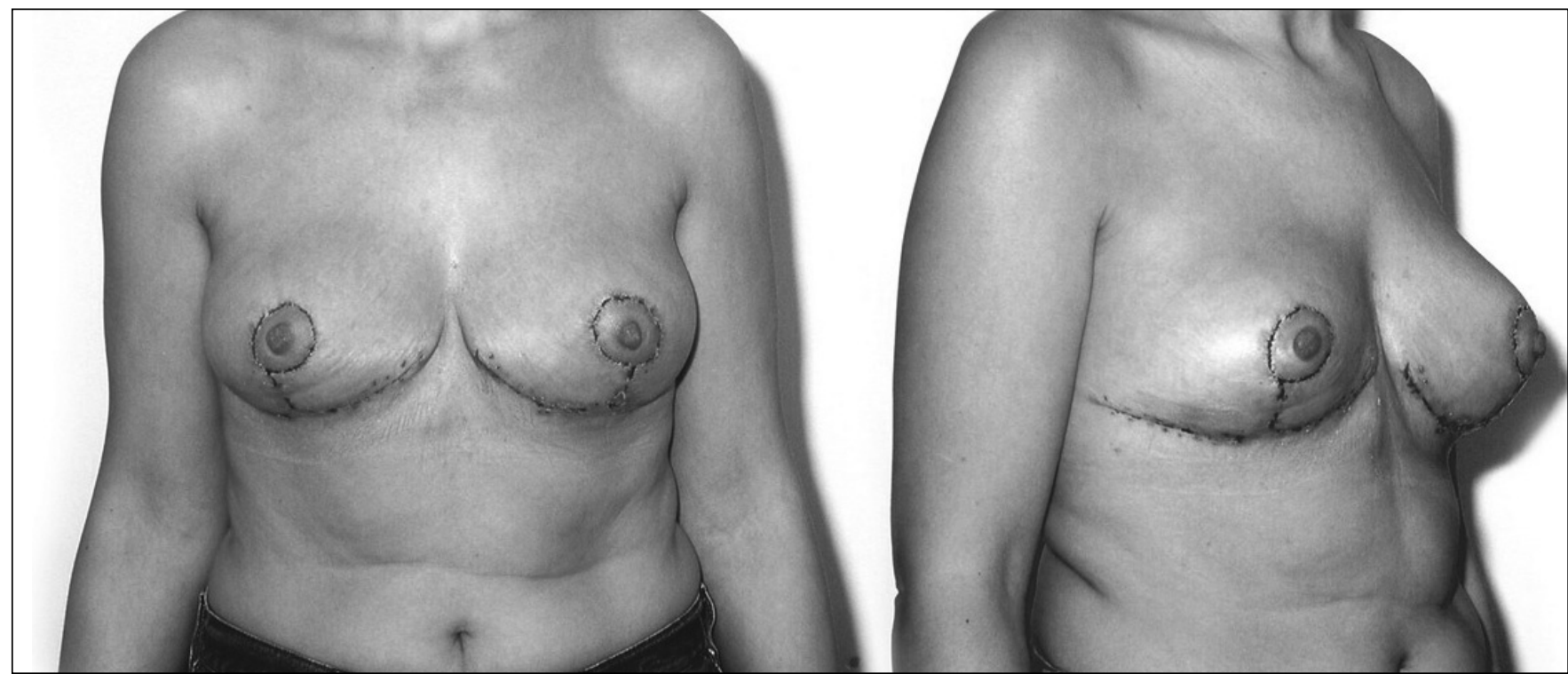

Figure 4) One-week postoperative result. The nipples are located just anterior to the inframammary fold

equilateral triangle that has its apex at the sternal notch and has sides measuring $21 \mathrm{~cm}$. However, he based his idea on a small sample of women between the ages of 18 and 39 years. However, breast reduction patients present at different ages and sizes. With increasing age and weight of the breasts, there is inferior migration of the nipple and IMF, resulting in ptosis and some lateral deviation (2). Strict adherence to Penn's measurements may not suit every patient. A slightly elongated triangle may be required for a more mature, slightly ptotic look in older and heavier patients. Balancing the new position of the nipple with the inferiorly migrated IMF would achieve the required location in these patients. Similarly, the laterally deviated nipple may need to be brought in medially to lie within the aesthetic breast meridian.

Many methods have been described to locate the new position of the NAC (1,3-5). The most acceptable location of the NAC is at the level of the IMF transposed on the anterior surface of the breast (6). This is usually accomplished by palpating a finger through the breast, which is placed at the level of the IMF (7). Other options include using large gynecological calipers (6) to transpose the position of the IMF on the anterior surface of the breast. The former is fairly subjective and can be inaccurate, especially in larger breasts where it is difficult to feel the finger through the breast tissue. The latter technique requires special instrumentation, which may not be readily available.

\section{CONCLUSIONS}

We find the geometrical calculation method to be an easily reproducible technique. It is quick, and no bulky instrumentation is required. The present technique may prove useful for trainees in plastic surgery to plan the breast reduction procedure preoperatively by accurately locating the new nipple position.

ACKNOWLEDGEMENT: Mathew Briggs (Department of Medical Illustration, Royal Preston Hospital, United Kingdom).

\section{REFERENCES}

1. Penn J. Breast reduction. Br J Plast Surg 1955;7:357-71.

2. Brown TP, Ringrose C, Hyland RE, Cole AA, Brotherston TM. A method of assessing female breast morphometry and its clinical application. Br J Plast Surg 1999;52:355-9.

3. Aufricht G. Mammaplasty for pendulous breasts; empiric and geometric planning. Plast Reconstr Surg (1946) 1949;4:13-29

4. Maliniac JW. Evaluation of principal mamma-plastic procedures. Plast Reconstr Surg (1946) 1949;4:359-73.

5. Gillies HD, McIndoe AH. The technique of mammaplasty in conditions of hypertrophy of the breast. Surg Gynaecol Obstetr 1939;68:658.

6. John W, Little SLS, Romm S. Reduction mammaplasty and mastopexy. In: Smith JW, ed. Grabb and Smith's Plastic Surgery, 4th edn. Boston: Little Brown and Company, 1991:1157-202.

7. Strombeck JO. Reduction mammaplasty. Surg Clin North Am 1971;51:453-69. 